\section{P65 GITELMAN SYNDROME: CASE REPORT OF A TODDLER FOLLOWING SALBUTAMOL INHALER}

${ }^{1}$ Vasanthee Sundram*, 'Edwina Daly, ${ }^{1}$ Mary Waldron. ${ }^{1}$ Tallaght University Hospital, Dublin, Ireland; ' Our Lady's Children's Hospital, Crumlin, Dublin, Ireland

10.1136/archdischild-2019-epa.420

Background Gitelman syndrome (GS), is an inherited autosomal recessive renal disorder characterized by hypokalemic metabolic alkalosis with significant hypomagnesemia and low urinary calcium excretion. It is a rare disorder which usually manifests in early adulthood with muscle weakness, fatigue, muscle cramps, and less commonly by abdominal pain, nausea and vomiting.

Case report We report on a 2 year old boy who presented to the Emergency Department with a two weeks history of coughing. His parents had been administering regular Salbutamol inhaler to control his symptoms.

He had a previous admission three months earlier and was discharged on inhaled Salbutamol to be used as required.

His weight was $11.6 \mathrm{kgs}$ (25-50th percentile), height was $87.5 \mathrm{~cm}$ (50th percentile) and BMI $15.2 \mathrm{Kg} / \mathrm{m}^{2}$

$\mathrm{He}$ was miserable on examination with mild recession, bilateral expiratory wheeze with crackles in both bases.

Initial laboratory investigations showed a normal full blood count, urea and electrolytes, a normal venous blood gas with a C - reactive protein of $45 \mathrm{mg} / \mathrm{L}$.

Chest $x$-ray reported patchy infective changes in the left lower lobe with diffuse perihilar inflammatory changes.

The patient was commenced on intravenous Amoxicillin and $2.5 \mathrm{mgs}$, oral steroids and nebulised Salbutamol to be administered every four hours.

On day 3 of admission, he was noted to be extremely lethargic and was barely responding to his mother's voice which was not in keeping with the improvement of his respiratory symptoms.

Repeated blood gas analysis showed a significant metabolic alkalosis ( $\mathrm{pH} 7.552)$ and hypokalemia (2.7 mmols/L) He was started on intravenous fluids with added $\mathrm{KCl} 20$ mmols/ $500 \mathrm{ml}$. Nebulised Salbutamol was changed to the inhaled form and Inhaled Fluticasone was added.

ECG showed flattened $T$ waves, possible $U$ waves and a QTc of 460. Urinary creatinine, phosphate, sodium, calcium and Magnesium were requested. A Renal ultrasound and sweat test were arranged which were subsequently normal.

The nephrology Team were consulted who confirmed the diagnosis of Gitelman syndrome and recommended regular Ibuprofen for three days. He made an uneventful recovery and his potassium and blood gas normalised after two days.

Discussion Gitelman Syndrome is often difficult to diagnose in Paediatrics because it usually presents in adolescence or early adulthood. Sudden cardiac arrest has been reported and it is therefore an extremely important condition to recognise particularly when prescribing potassium lowering agents like Salbutamol and Steroids.

\section{P66 A CASE OF PSEUDOHYPONATREMIA DUE TO HYPERCHOLESTEROLAEMIA IN A PATIENT WITH CHOLESTASIS}

Hafiz Shafiq Butt*, Lubna Mahmood, Alfonso Herrera. St Luke's Hospital, Kilkenny, Ireland

10.1136/archdischild-2019-epa.421
Introduction Serum consists of water (93\% of serum volume) and non aqueous components, mainly lipids and proteins $(7 \%$ of serum volume). Sodium is restricted to serum water. In states of hyperlipidaemia or hyperprotenaemia, there is an increased mass of non aqueous components of serum and a concomitant decrease in the proportion of serum composed of water.

The term pseudohyponatraemia refers to the apparently low sodium concentration found in plasma when blood specimens with high concentration of either lipid or protein are analysed by tradional methods.

Pseudohyponatraemia secondary to hypercholesterolaemia is a rare condition. In the diagnostic approach for the patients with hyponatraemia, it should always be differentiated during the initial steps. High concentration of intravascular protein or lipid ' dilute" the plasma sodium concentration, but do not alter the solute concentrations of intracellular or interstitial fluid compartments. Thus hyponatraemia assosiated with hyperlipidaemia or hyperprotenamia can be considered artifactual.

Case report Two years old boy was evaluated for seven weeks history of cholestatic Jaundice. During the workup for cholestasis, a significant drop in serum sodium, $120 \mathrm{mmol} / \mathrm{L}$ was noted. Child was asymptomatic apart from Jaundice. Serum Cholesterol level was significantly raised to $52.2 \mathrm{mmol} / \mathrm{L}$ (normal 2 - 5). Triglyceride and LDL was unavailable due to icterus, HDL was 0.45 (normal 1-2) . A concomitant Sodium level checked on Spot gas analyser was $139 \mathrm{mmol} / \mathrm{L}$ (normal).

Other Labs included raised ALT, AST, total bilurubin, alkaline phosphatase and Gamma GT, slightly low total protein and albumin. Viral Hepatitis screen was negative. Autoantibodies negative. Serum Ceruloplasmins, alphafetoproteins, and alpha1 antitrypsin levels were normal. Abdominal Ultrasound showed Fatty liver without biliary dilatation. Needle liver biopsy showed paucicity of bile ducts. Comprehensive genetic testing did not reveal a cause for his cholestasis. Later on, he also developed xanthomata on his fingers.

A final diagnosis of Cholestasis with bile duct paucity of unknown aetiology was made. LFT remained abnormal six months into the illness and is under followup by Gastroenterologist. Repeat Liver biopsy showed disease progression. He is on Ursodeoxycholic acid, AquaDEK and oral vitamin $\mathrm{K}$.

Conclusion This case shows that hypercholesterolemia can cause pseudohyponatraemia. It highlights that If there is any suspicion regarding a low serum Sodium in the presence of cholestasis, a serum Sodium should be re tested using blood gas analyser as this method is not subject to interference from hypercholesterolaemia.

\section{P67 CASE REPORT: MANAGEMENT OF A NEONATE WITH BRACHIAL ARTERY THROMBOSIS}

${ }^{1}$ Samy Allawendy*, ${ }^{1}$ Cormac Duff, ${ }^{1}$ Emmanuel Osakwe, ${ }^{1}$ Dara Gallagher, ${ }^{2}$ Patricia Eadie, ${ }^{2}$ Saima Aslam. ${ }^{1}$ SUH, Sligo, Ireland; ${ }^{2}$ OLCHC, Dublin, Ireland

10.1136/archdischild-2019-epa.422

Introduction Neonatal spontaneous arterial thromboembolism is a rare phenomenon with a high risk of morbidity and mortality. Currently, there is little information regarding common risk factors, diagnostic strategies, therapeutic interventions, and outcomes of this condition. 